REGARDS

SUR LEECONOMIE ALLEMANDE

BULLETIN ECONOMIQUE DU CRAC

\section{Regards sur l'économie allemande}

Bulletin économique du CIRAC

$77 \mid 2006$

Varia

\title{
Patriotisme sportif et responsabilité économique
}

\section{René Lasserre}

\section{OpenEdition}

Journals

Édition électronique

URL : http://journals.openedition.org/rea/534

DOI : $10.4000 /$ rea. 534

ISBN : 978-2-8218-0850-8

ISSN : 1965-0787

Éditeur

CIRAC

Édition imprimée

Date de publication : 1 juillet 2006

Pagination : 1-2

ISSN : 1156-8992

Référence électronique

René Lasserre, "Patriotisme sportif et responsabilité économique ", Regards sur l'économie allemande [En ligne], 77 | juillet 2006, mis en ligne le 30 avril 2008, consulté le 22 septembre 2020. URL : http:// journals.openedition.org/rea/534; DOI : https://doi.org/10.4000/rea.534 


\section{Patriotisme sportif et responsabilité économique}

Qu'elle sorte ou non victorieuse du tournoi, l'Allemagne aura réussi sa Coupe du monde. Tout entière rassemblée derrière une équipe rajeunie et déterminée, elle a démontré à la fois sa confiance en ellemême, la générosité de son enthousiasme et la sincérité de son ouverture au monde. L'événement ne pouvait tomber plus heureusement dans le calendrier, six mois après que le pays a exprimé sa volonté de sortir de l'immobilisme politique en portant au pouvoir un gouvernement de grande coalition et alors même que l'économie allemande renoue enfin avec la croissance. Le Mondial vient ainsi à point nommé pour conforter l'image d'un pays qui, soumis depuis quinze ans à la difficile épreuve de son unification, et au prix de multiples efforts, est en passe de surmonter ses doutes et regarde à nouveau l'avenir en face.

Il n'y a pas lieu de s'inquiéter d'un soit disant renouveau de patriotisme que suscite en Allemagne la fête du football, sport national par excellence. Ce patriotisme reste de bon aloi tant qu'il témoigne, au delà du soutien mérité à l'équipe nationale, de la confiance d'un peuple en lui-même et de sa foi dans l'avenir. Il est d'autres formes de patriotisme plus dangereuses qui se nourrissent de craintes et de replis identitaires. Le fait que les Allemands manifestent ainsi une identité solidaire et ouverte au monde devrait au contraire nous rassurer, car il est de bon augure pour l'Europe. C'est en relevant le défi du changement et en décidant de remettre leur maison en ordre que nos voisins ont retrouvé confiance en euxmêmes. Et à l'instar d'autres pays européens aux moyens plus modestes qui n'avaient guère d'autre choix, ils montrent à leur tour la marche à suivre pour que les sociétés et les économies européennes tiennent toute leur place et jouent pleinement leur rôle dans un monde globalisé.

Pour nos partenaires allemands, cette compétition-là est encore loin d'être gagnée, mais au moins est-elle désormais résolument engagée. L'étude que nous publions dans le présent numéro sur la politique de consolidation budgétaire et la réforme fiscale montre combien ce chantier domestique est à la fois ambitieux et semé d'embûches. En érigeant la consolidation budgétaire et financière au rang de toute première priorité, le gouvernement Merkel s'est engagé dans une entreprise de grande envergure qui dépasse largement la seule réduction des déficits et vise à réformer le système fiscal en profondeur pour assurer durablement la compétitivité de l'économie. La consolidation budgétaire constitue la priorité immédiate car il importe de toute urgence de remettre les finances publiques à flots et de sortir le pays de la spirale de l'endettement. Le choix audacieux mais risqué de la hausse des impôts par une augmentation de la TVA ne répond pas uniquement à un impératif d'efficacité financière à court terme mais également à celui d'une rentabilité fiscale à long terme par un rééquilibrage des prélèvements en direction de la 
fiscalité indirecte, par ailleurs conforme à la norme moyenne européenne. Par là même, le gouvernement de grande coalition entend dégager des marges de manoeuvre suffisantes pour alléger très sensiblement et simplifier la fiscalité des entreprises, conditions nécessaires d'un système fiscal compétitif et attractif, favorable à l'investissement.

La restructuration du système fiscal dans lequel s'est engagé le gouvernement Merkel constitue ainsi un élément crucial pour la réorganisation du système économique et social allemand, car à travers la résorption des déficits et le redéploiement du prélèvement, c'est un nouvel équilibre qu'il entend promouvoir entre l'efficacité fiscale et la sauvegarde de la compétitivité économique. Sous l'apparence d'un compromis, la voie choisie par les deux grands partis est peut-être plus novatrice qu'il n'y paraît : la compétitivité économique ne passe pas nécessairement par moins d'impôt, mais par un impôt efficace qui taxe suffisamment la richesse lorsqu'elle se consomme plutôt qu'au moment où elle se crée en pénalisant le travail et l'investissement. Outre qu'il favorise la croissance, un système fiscal productif permet de réduire les prélèvements sociaux fondés sur l'activité et constitue ainsi un préalable à une réforme du financement des régimes de protection.

Reste que ce nouvel équilibre sera difficile à établir tant le système fiscal allemand est complexe et cloisonné, notamment pour la fiscalité des entreprises. Outre que celle-ci est extrêmement hétérogène selon la taille et le statut de l'entreprise, sa refonte se heurtera au poids important de la taxe professionnelle et à son verrouillage politique par les communes au sein du fédéralisme. L'accord des deux grands partis devrait cependant permettre de surmonter ces résistances.

On le voit: la hausse prochaine de la TVA n'a pas pour simple finalité conjoncturelle de combler le déficit, voire, comme certains le disent, de faire supporter cette cure d'austérité par les voisins européens opérant sur le marché allemand. L'enjeu est d'une tout autre ampleur: en initiant la refonte de son système fiscal, l'Allemagne commence à tourner la page d'un Etat-providence désormais à bout de souffle et s'engage résolument sur la voie d'un nouveau système de régulation fondé sur l'impératif de la compétitivité globale.

René Lasserre

(27 juin 2006) 